\title{
Atomic Data for Plasma Spectroscopy: The CHIANTI Database, Improvements and Challenges
}

\author{
Giulio Del Zanna ${ }^{1, *(1)}$ and Peter R. Young 2,3 (1) \\ 1 Department of Applied Mathematics and Theoretical Physics, Centre for Mathematical Sciences, \\ University of Cambridge, Wilberforce Road, Cambridge CB3 0WA, UK \\ 2 NASA Goddard Space Flight Center, Code 671, Greenbelt, MD 20771, USA; peter.r.young@nasa.gov \\ 3 Mathematics, Physics and Electrical Engineering, Northumbria University, \\ Newcastle Upon Tyne NE1 8ST, UK \\ * Correspondence: gd232@cam.ac.uk
}

Received: 30 July 2020; Accepted: 17 August 2020; Published: 20 August 2020

\begin{abstract}
CHIANTI is an atomic database and software package for modeling emission lines and continua from hot astrophysical plasmas. It is freely available to all researchers and has been widely used in the Heliophysics and Astrophysics communities for almost 25 years. In this review, we summarize the properties of the current version of the database and give an overview of the relevant atomic processes. We also discuss progress towards a complete implementation of collisional-radiative modeling, simultaneously solving for atomic level and ion populations for individual elements.
\end{abstract}

Keywords: A\&M databases; data assessment; plasma modeling codes

\section{Introduction}

In this review, we describe the current status of the atomic data needed to study the spectral line emission from astrophysical and laboratory plasma, recent improvements in the data and modelling, and a few challenges that lie ahead. Emphasis is given on the developments within the CHIANTI atomic database and to future potential extensions, although the issues discussed here are very general.

For a general overview of the CHIANTI database and its developments see [1]. The CHIANTI database was first released in 1996 [2], mostly to address the needs of the solar community, as SoHO was providing a large amount of data, especially spectra in the EUV and UV, which needed accurate atomic data for their interpretation. At the time, there was no atomic database freely available. The data have been integrated with a suite of IDL codes, and Python versions of some of the programs are also available at CHIANTIPy ${ }^{1}$. A set of new Python programs is also under development by one of us (GDZ).

As emphasis was on solar coronal observations, the atomic data that were originally collected included the most abundant elements and ions, and the modelling assumed optically thin emission and zero density for the ion charge states. Over the years CHIANTI has become a reference database also for astrophysical and laboratory plasma in general.

Within astrophysics, CHIANTI data are widely used within a range of modelling codes such as the photoionization codes Cloudy [3], MOCASSIN [4], XSTAR [5], spectral modelling of supernovae such as TARDIS [6], and the more general codes such as ATOMDB [7], PINTofALE [8], DIPER [9], and SPEX [10] (this list is not exhaustive). These data are used to analyze the wealth of spectra (from the

1 http:// chiantipy.sourceforge.net. 
X-rays to the infrared) of solar and astrophysical plasma in a variety of environments. CHIANTI data are also used to study laboratory plasma. CHIANTI basic atomic rates have also been integrated within VAMDC ${ }^{2}$, a general portal for atomic and molecular data (see Albert et al. [11], this issue).

The number of direct citations to the CHIANTI papers, shown in Figure 1, is an indication of the popularity of the database, although the actual number of indirect citations (via other modelling codes which use CHIANTI data) is far higher.

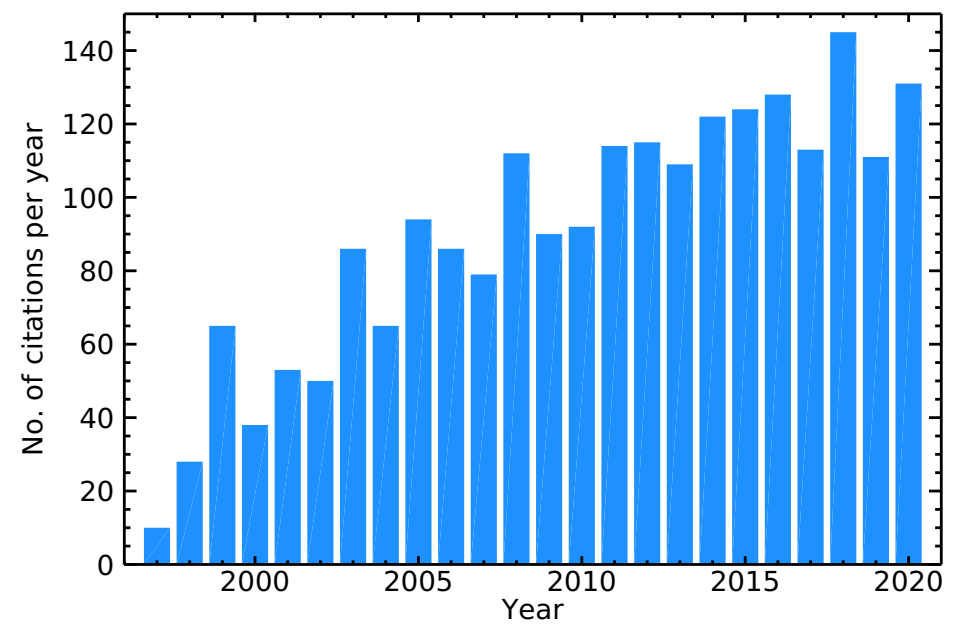

Figure 1. Current status of yearly direct citations to the CHIANTI papers.

CHIANTI data are also widely used to calculate the optically thin radiative losses in most MHD (see e.g., the review by Gombosi et al. [12]) and hydrodynamic (see, e.g., Bradshaw and Mason [13], Allred et al. [14]) codes. CHIANTI also contains routines to calculate continuum processes which are not reviewed here. As all these atomic data are also used to analyze broad-band imaging data such as those of the Solar Dynamics Observatory AIA instrument, the issue of completeness has become important, as e.g., pointed out by $[15,16]$.

Also, as technology improves, higher-resolution spectroscopy is clearly showing the need to improve accuracy in the spectral line identifications, wavelengths and atomic rates. This also raises the issue of how to quantify accuracy and uncertainty. Finally, detailed comparisons with solar observations indicate that improvements in the modelling are necessary. They include for example non-equilibrium effects such as non-Maxwellian electron distributions (NMED), time-dependent ionization (TDI), but also various effects which modify the ion charge states, such as photoionization, charge transfer, and density-dependent rates. Some of these effects are also very relevant for a wide range of astrophysical and laboratory plasma, but are normally not all included in models.

\section{Atomic Processes within an Ion}

Table 1 presents an overview of the neutrals and ions currently available within CHIANTI version 10, and for which a complete set of atomic rates (collisional and radiative) are available. The table also lists the number of levels in the atomic models, and a key to the type of electron collisional excitation rates available.

\subsection{Electron Collisional Excitation (CE)}

Perhaps the most important (and difficult to calculate accurately) sets of rates are those for collisional excitation by electron impact (CE). After the pioneering work of M.J. Seaton (University

2 http://portal.vamdc.eu. 
College London), P. Burke (Queens University of Belfast), and A. Burgess (University of Cambridge) the second generation of atomic physicists produced a large amount of data since the 1970s.

After the early calculations in the Distorted Wave approximation (DW), a significant effort (mostly within the Iron Project)) over decades was put in place to develop various codes for scattering calculations with the $R$-matrix method, see, e.g., $[17,18]$.

Within CHIANTI, data are collected from the literature, by assessing them in a variety of ways. One is to check for consistency between the thermally averaged cross-sections and the high-energy limits in the scaled domain as formulated by [19]. Another way is to compare, when available, data calculated with different codes and methods. Ultimately, as CE rates are the main populating process for coronal plasma, a key part of the assessment is a comparison between predicted line intensities and well-calibrated observations (see the summary in [20]). Another important issue is the completeness of the data. CE rates without the associated radiative data are not very useful for modelling. Unfortunately, lack of completeness in published rates has been very common in the literature. Another important issue regards the availability of the data. Within our experience, we had many cases, even very recently, when original data associated with a publication were lost by the author. Every journal should make sure that atomic data associated with a publication are made available electronically.

For many isoelectronic sequences, the most complete sets of $C E$ rates are those produced by the UK Atomic Processes for Astrophysical Plasmas (APAP) network ${ }^{3}$ (PI: N.R.Badnell). The UK APAP work has received funding from STFC (UK), only for the specific purpose of atomic calculations of relevance to astrophysics, which means that significant code developments have not been carried out. The UK APAP network data have been included in all major atomic modelling codes for astrophysics (including CHIANTI), and also incorporated into $\mathrm{ADAS}^{4}$, the database for the magnetic fusion community.

These calculations are carried out in the R-matrix inner region in LS-coupling, while for the outer region the intermediate-coupling frame transformation method (ICFT) [21] is generally adopted. For a discussion on how the results compare with those with the Breit-Pauli $R$-matrix or the relativistic $R$-matrix DARC (developed by P. H. Norrington and I. P. Grant), see [22]. For a comparison between ICFT, DARC, and the results of the B-spline $R$-matrix method for N IV see [23]. Very good agreement for the lower states was found. However, $C E$ rates to highly excited levels can be very inaccurate, because of the limitation in the CI and CC expansions. The B-spline $R$-matrix (BSR) method (see, e.g., [24,25] for details) can achieve a much better target structure description than the other methods, but is computationally demanding. The BSR codes have mostly been used to calculate cross sections for neutrals and low charge states. For simple systems, the convergent close-coupling (CCC) method of [26] and its relativistic version typically produce very accurate CE rates.

A list of recent UK APAP network calculations is given in [22]. In addition, CE rates for all the ions in the C-like [27] and N-like sequences (Mao et al., in preparation) have recently been calculated. Plans are in place to calculate the ions in the O-like sequence, and in the future the $\mathrm{H}$ - and He-like ions.

Within the CHIANTI database, CE rates for several ions are taken from the literature, when calculations are deemed more accurate than the isoelectronic sequence work from the UK APAP network. A short review is provided in [20], while more details are given as comments in the data files. Overall, the status of the CE rates is that they will soon be complete for the sequences from $\mathrm{H}$ - to O-like. CHIANTI version 10 will include the sequence data for the $\mathrm{Be}-, \mathrm{Mg}$-, and C-like isoelectronic sequences, plus additional data for other ions, as shown in Table 1.

Originally, the CHIANTI database only included CE rates from the states that are metastable for low-density astrophysical plasma, and for the more abundant elements. Since version 8 [28], minor ions and all CE rates among the states are included, so modelling of high-density laboratory

\footnotetext{
www.apap-network.org.

open.adas.ac.uk.
} 
plasma can be carried out. Also, the CE rates are directly included at the calculated temperatures, instead of being spline fitted, to preserve the original rates. The data are provided in a scaled domain, and two additional temperatures (at threshold and at the high-energy limit) are added, so users can obtain rates also outside the original temperature range.

Significant work still needs to be carried out for the other sequences, with large-scale calculations. As shown in a series of papers dedicated to the calculations of the CE rates for the $n=4$ states in iron ions (see e.g., Fe X [29]), the DW method for some states significantly underestimates the CE rates. Furthermore, cascading effects from higher states also need to be taken into account. ICFT calculations up to $n=7$ levels are now routinely carried out to improve the CE rates of the $n=4,5$ states. However, it turns out that $C E$ rates and the associated transition probabilities are not easy to calculate for the higher states as the configuration expansion is unbalanced, given the absence of the bound states above the limit of the calculation, and the continuum states. A possible solution is to extrapolate the $\mathrm{CE}$ rates using the values for the $n=4,5$ states, as done for helium [30], and suggested for the $\mathrm{H}$ - and He-like ions by [31].

For complex ions, there is an additional problem for states with close energy, the same $J$-value and parity. The strong mixing can change substantially the oscillator strengths and relative $\mathrm{CE}$ rates, depending on the target configurations included in the configuration-interaction (CI) and close-coupling (CC) expansions. This is a general problem present in any method of calculation, and often affecting the strongest lines in an ion, as for Fe XI [32]. The same problem affected the calculations for Fe VIII by [33,34], as discussed in [35,36].

The problem is partially resolved introducing term energy corrections (TEC) in the scattering calculations, as shown in [36]. However, whenever experimental energies are not known or questionable, we have a circular problem. Such an example is Fe vII: a large-scale ICFT calculation by [37] was benchmarked against well-calibrated Hinode EIS observations by [38], finding several large discrepancies in the strongest lines for this ion. Alternative tentative identifications to those available at NIST, due to Ekberg, were proposed. On the other hand, different identifications were proposed by [39], where questions on the validity of the CE rates were also raised. Later, [40] carried out another large-scale scattering calculation with the B-spline Breit-Pauli R-matrix method, finding generally similar CE rates as those obtained by [37]. Considering the benchmark structure calculations in [38], for both of these scattering calculations the targets are not very accurate, so it appears that improvements in both the atomic calculations and the line identifications are needed.

The approach in some databases is to provide multiple sets of atomic rates, so the user could experiment. However, that has not been the CHIANTI approach, so in each version we try to provide the best sets of atomic data. Clearly, continous improvements are necessary, which complicates the propagation of the updates into other databases. 
Table 1. Neutrals and ions currently present in the CHIANTI database.

\begin{tabular}{|c|c|c|c|c|c|c|c|c|c|c|c|c|c|c|c|c|c|}
\hline & I & II & III & IV & V & VI & VII & VIII & IX & $\mathrm{X}$ & XI & XII & XIII & XIV & $\mathbf{X V}$ & XVI XVII XVIII XIX XXXXXI & XXII XXIII XXIV XXV XXVI XXVII XXVIII \\
\hline $\mathrm{H}$ & $\begin{array}{c}\text { OA } \\
25\end{array}$ & & & & & & & & & & & & & & & & \\
\hline $\mathrm{He}$ & $\begin{array}{l}\text { OA } \\
49\end{array}$ & $\begin{array}{l}\text { OA } \\
25\end{array}$ & & & & & & & & & & & & & & & \\
\hline C & $\begin{array}{l}\text { RM } \\
42\end{array}$ & $\begin{array}{l}\text { A12 } \\
204\end{array}$ & $\begin{array}{l}\mathrm{A} 14 \\
75\end{array}$ & $\begin{array}{c}\text { A11 } \\
63 \\
\text { AI: } 860\end{array}$ & $\begin{array}{c}\text { OA } \\
127 \\
\mathrm{AI}: 450\end{array}$ & $\begin{array}{l}\mathrm{OA} \\
25\end{array}$ & & & & & & & & & & & \\
\hline $\mathrm{N}$ & $\begin{array}{c}\mathrm{RM} \\
50\end{array}$ & $\begin{array}{l}\mathrm{RM} \\
58\end{array}$ & $\begin{array}{l}\text { A12 } \\
204\end{array}$ & $\begin{array}{l}\text { A14 } \\
238\end{array}$ & $\begin{array}{c}\text { A11 } \\
63 \\
\text { AI:860 }\end{array}$ & $\begin{array}{c}\text { OA } \\
127 \\
\text { AI: } 450\end{array}$ & $\begin{array}{l}\text { OA } \\
25\end{array}$ & & & & & & & & & & \\
\hline $\mathrm{O}$ & $\begin{array}{c}\mathrm{RM} \\
7\end{array}$ & $\begin{array}{c}\mathrm{RM} \\
35\end{array}$ & $\begin{array}{l}\text { A20 } \\
177\end{array}$ & $\begin{array}{l}\text { A12 } \\
204\end{array}$ & $\begin{array}{l}\text { A14 } \\
166\end{array}$ & $\begin{array}{c}\text { A11 } \\
63 \\
\text { AI: } 860\end{array}$ & $\begin{array}{c}\text { OA } \\
127 \\
\text { AI: } 450\end{array}$ & $\begin{array}{c}\text { OA } \\
25\end{array}$ & & & & & & & & & \\
\hline $\mathrm{Ne}$ & & $\begin{array}{l}\mathrm{A} 07 \\
138\end{array}$ & $\begin{array}{c}\mathrm{RM}+\mathrm{DW} \\
86\end{array}$ & $\begin{array}{c}\mathrm{RM} \\
22\end{array}$ & $\begin{array}{l}\text { A20 } \\
304\end{array}$ & $\begin{array}{l}\text { A12 } \\
204\end{array}$ & $\begin{array}{l}\text { A14 } \\
166\end{array}$ & $\begin{array}{c}\text { A11 } \\
63 \\
\text { AI:860 }\end{array}$ & $\begin{array}{c}\text { OA } \\
127 \\
\text { AI:450 }\end{array}$ & $\begin{array}{l}\mathrm{OA} \\
36\end{array}$ & & & & & & & \\
\hline $\mathrm{Na}$ & & $\begin{array}{l}\text { A10 } \\
209\end{array}$ & $\begin{array}{l}\text { A07 } \\
195\end{array}$ & $\begin{array}{c}\mathrm{RM}+\mathrm{I} \\
10\end{array}$ & $\begin{array}{c}\mathrm{I} \\
13\end{array}$ & $\begin{array}{l}\text { A20 } \\
410\end{array}$ & $\begin{array}{l}\text { A12 } \\
204\end{array}$ & $\begin{array}{l}\text { A14 } \\
166\end{array}$ & $\begin{array}{l}\text { A11 } \\
204\end{array}$ & $\begin{array}{l}\text { OA } \\
49\end{array}$ & $\begin{array}{c}\text { OA } \\
25\end{array}$ & & & & & & \\
\hline $\mathrm{Mg}$ & & $\begin{array}{c}\text { A09 } \\
32 \\
\text { AI:129 }\end{array}$ & $\begin{array}{l}\text { A10 } \\
209\end{array}$ & $\begin{array}{l}\text { A07 } \\
195\end{array}$ & $\begin{array}{c}\mathrm{RM}+\mathrm{DW} \\
86\end{array}$ & $\begin{array}{c}\mathrm{RM}+\mathrm{DW} \\
72\end{array}$ & $\begin{array}{c}\text { A20 } \\
450\end{array}$ & $\begin{array}{l}\text { A12 } \\
204\end{array}$ & $\begin{array}{l}\text { A14 } \\
166\end{array}$ & $\begin{array}{c}\mathrm{A} 11 \\
63 \\
\mathrm{AI}: 860\end{array}$ & $\begin{array}{c}\text { OA } \\
127 \\
\text { AI: } 450\end{array}$ & $\begin{array}{c}\text { OA } \\
25\end{array}$ & & & & & \\
\hline $\mathrm{Al}$ & & $\begin{array}{c}\mathrm{A} 14 \\
60\end{array}$ & $\begin{array}{c}\text { A09 } \\
32 \\
\text { AI:129 }\end{array}$ & $\begin{array}{l}\text { A10 } \\
209\end{array}$ & $\begin{array}{l}\text { A07 } \\
195\end{array}$ & $\begin{array}{c}\text { I } \\
10\end{array}$ & $\begin{array}{c}\text { DW } \\
15\end{array}$ & $\begin{array}{l}\text { A20 } \\
482\end{array}$ & $\begin{array}{l}\text { A12 } \\
204\end{array}$ & $\begin{array}{l}\text { A14 } \\
166\end{array}$ & $\begin{array}{c}\text { A11 } \\
63 \\
\text { AI: } 860\end{array}$ & $\begin{array}{c}\text { OA } \\
127 \\
\text { AI: } 450\end{array}$ & $\begin{array}{c}\text { OA } \\
25\end{array}$ & & & & \\
\hline $\mathrm{Si}$ & & $\begin{array}{l}\mathrm{RM} \\
29\end{array}$ & $\begin{array}{l}\text { A14 } \\
82\end{array}$ & $\begin{array}{c}\text { A09 } \\
32 \\
\text { AI:129 }\end{array}$ & $\begin{array}{l}\text { A10 } \\
209\end{array}$ & $\begin{array}{l}\text { A07 } \\
195\end{array}$ & $\begin{array}{l}\text { DW } \\
86\end{array}$ & $\begin{array}{c}\mathrm{RM}+\mathrm{DW} \\
72\end{array}$ & $\begin{array}{l}\text { A20 } \\
590\end{array}$ & $\begin{array}{l}\mathrm{A} 12 \\
204\end{array}$ & $\begin{array}{l}\text { A14 } \\
166\end{array}$ & $\begin{array}{c}\text { A11 } \\
63 \\
\text { AI: } 860\end{array}$ & $\begin{array}{c}\text { OA } \\
127 \\
\text { AI: } 450\end{array}$ & $\begin{array}{c}\text { OA } \\
25\end{array}$ & & & \\
\hline $\mathrm{P}$ & & & & $\begin{array}{l}\text { A14 } \\
117\end{array}$ & $\begin{array}{c}\text { A09 } \\
32 \\
\text { AI:129 }\end{array}$ & $\begin{array}{l}\text { A10 } \\
209\end{array}$ & $\begin{array}{c}\mathrm{A} 07 \\
3\end{array}$ & $\begin{array}{c}\text { DW } \\
10\end{array}$ & $\begin{array}{c}\text { DW } \\
15\end{array}$ & $\begin{array}{l}\text { A20 } \\
590\end{array}$ & $\begin{array}{l}\text { A12 } \\
204\end{array}$ & $\begin{array}{l}\text { A14 } \\
166\end{array}$ & $\begin{array}{l}\text { A11 } \\
204\end{array}$ & $\begin{array}{c}\mathrm{OA} \\
45\end{array}$ & $\begin{array}{l}\text { OA } \\
25\end{array}$ & & \\
\hline$S$ & $\begin{array}{c}\mathrm{RM} \\
5\end{array}$ & $\begin{array}{c}\mathrm{RM} \\
70\end{array}$ & $\begin{array}{c}\mathrm{RM} \\
53\end{array}$ & $\begin{array}{l}\mathrm{RM} \\
52\end{array}$ & $\begin{array}{c}\text { A14 } \\
159\end{array}$ & $\begin{array}{c}\text { A09 } \\
32 \\
\text { AI:129 }\end{array}$ & $\begin{array}{l}\text { A10 } \\
209\end{array}$ & $\begin{array}{l}\text { A07 } \\
195\end{array}$ & $\begin{array}{l}\text { DW } \\
86\end{array}$ & $\begin{array}{c}\mathrm{RM}+\mathrm{DW} \\
72\end{array}$ & $\begin{array}{l}\mathrm{A} 20 \\
590\end{array}$ & $\begin{array}{l}\mathrm{A} 12 \\
204\end{array}$ & $\begin{array}{l}\text { A14 } \\
166\end{array}$ & $\begin{array}{c}\text { A11 } \\
63 \\
\text { AI:860 }\end{array}$ & $\begin{array}{c}\text { OA } \\
127 \\
\text { AI: } 450\end{array}$ & $\begin{array}{c}\text { OA } \\
25\end{array}$ & \\
\hline $\mathrm{Cl}$ & & $\begin{array}{c}\mathrm{RM} \\
5\end{array}$ & $\begin{array}{c}\text { RM } \\
5\end{array}$ & $\begin{array}{c}\mathrm{RM} \\
5\end{array}$ & & $\begin{array}{l}\text { A14 } \\
171\end{array}$ & & & & $\begin{array}{c}\text { DW } \\
10\end{array}$ & $\begin{array}{c}\text { DW } \\
15\end{array}$ & $\begin{array}{l}\text { A20 } \\
590\end{array}$ & $\begin{array}{l}\text { A12 } \\
204\end{array}$ & $\begin{array}{l}\text { A14 } \\
166\end{array}$ & $\begin{array}{l}\text { A11 } \\
204\end{array}$ & $\begin{array}{cc}\text { OA } & \text { OA } \\
49 & 25\end{array}$ & \\
\hline
\end{tabular}


Table 1. Cont.

\begin{tabular}{|c|c|c|c|c|c|c|c|c|c|c|c|c|c|c|c|c|c|c|c|c|c|c|c|c|c|c|c|}
\hline & I II & III & IV & $\mathbf{V}$ & VI & VII & VIII & IX & $X$ & $\mathbf{X I}$ & XII & XIII & XIV & $\mathbf{X V}$ & XVI & XVII & XVIII & XIX & $X X$ & XXI & XXII & I XXIII & XXIV & XXV & \multicolumn{3}{|c|}{ XXVI XXVII XXVIII } \\
\hline $\mathrm{Ar}$ & & $\begin{array}{c}\text { RM I } \\
5\end{array}$ & $\begin{array}{c}\text { I RM } \\
30\end{array}$ & $\begin{array}{c}\mathrm{RM} \\
5\end{array}$ & & $\begin{array}{l}\text { A14 } \\
196\end{array}$ & $\begin{array}{c}\text { A09 } \\
32 \\
\text { AI:129 }\end{array}$ & $\begin{array}{l}\text { A10 } \\
209\end{array}$ & $\begin{array}{l}\text { A07 } \\
195\end{array}$ & $\begin{array}{c}\text { DW } \\
86\end{array}$ & $\begin{array}{l}\text { DW } \\
725\end{array}$ & $\begin{array}{l}\text { A20 } \\
590\end{array}$ & $\begin{array}{l}\text { A12 } \\
204\end{array}$ & $\begin{array}{l}\text { A14 } \\
166\end{array}$ & \begin{tabular}{|c|} 
A11 \\
63 \\
AI: 860
\end{tabular} & $\begin{array}{c}\mathrm{OA} \\
127 \\
\mathrm{AI}: 450\end{array}$ & $\begin{array}{c}\text { OA } \\
25\end{array}$ & & & & & & & & & & \\
\hline K & & & $\begin{array}{c}\mathrm{RM} \\
5\end{array}$ & $\begin{array}{c}\text { RM I } \\
5\end{array}$ & $\begin{array}{c}\mathrm{RM} \\
5\end{array}$ & & $\begin{array}{l}\text { A14 } \\
209\end{array}$ & $\begin{array}{c}\text { A09 } \\
32 \\
\text { AI:129 }\end{array}$ & $\begin{array}{l}\text { A10 } \\
209\end{array}$ & $\begin{array}{c}\text { A07 } \\
3\end{array}$ & $\begin{array}{c}\text { DW } \\
10\end{array}$ & $\begin{array}{c}\text { DW } \\
15\end{array}$ & $\begin{array}{l}\text { A20 } \\
590\end{array}$ & $\begin{array}{l}\text { A12 } \\
204\end{array}$ & $\begin{array}{c}\text { A14 } \\
166\end{array}$ & $\begin{array}{l}\text { A11 } \\
204\end{array}$ & $\begin{array}{c}\text { OA } \\
49\end{array}$ & $\begin{array}{c}\text { OA } \\
25\end{array}$ & & & & & & & & & \\
\hline $\mathrm{Ca}$ & $\begin{array}{c}\text { RM } \\
41\end{array}$ & & & $\begin{array}{c}\mathrm{RM} \\
5\end{array}$ & $\begin{array}{c}\text { RM L } \\
5\end{array}$ & $\begin{array}{c}\text { DW } \\
27\end{array}$ & $\begin{array}{c}\mathrm{RM} \\
40\end{array}$ & $\begin{array}{l}\text { A14 } \\
220\end{array}$ & $\begin{array}{c}\text { A09 } \\
32 \\
\text { AI:129 }\end{array}$ & $\begin{array}{l}\text { A10 } \\
209\end{array}$ & $\begin{array}{c}\text { A07 } \\
195\end{array}$ & $\begin{array}{c}\text { DW } \\
86\end{array}$ & $\begin{array}{c}\mathrm{RM} \\
84\end{array}$ & $\begin{array}{l}\text { A20 } \\
590\end{array}$ & $\begin{array}{l}\text { A12 } \\
204\end{array}$ & $\begin{array}{c}\text { A14 } \\
166\end{array}$ & $\begin{array}{c}\text { A11 } \\
63 \\
\text { AI: } 860\end{array}$ & $\begin{array}{c}\mathrm{OA} \\
127 \\
\mathrm{AI}: 450\end{array}$ & $\begin{array}{c}\text { OA } \\
25\end{array}$ & & & & & & & & \\
\hline $\mathrm{Ti}$ & & & & & & & & & & $\begin{array}{l}\text { A14 } \\
283\end{array}$ & $\begin{array}{c}\text { A09 } \\
32 \\
\text { AI:129 }\end{array}$ & $\begin{array}{l}\text { A10 } \\
209\end{array}$ & $\begin{array}{c}\text { A07 } \\
3\end{array}$ & $\begin{array}{c}\text { DW } \\
10\end{array}$ & $\begin{array}{c}\text { DW } \\
72\end{array}$ & $\begin{array}{l}\text { A20 } \\
590\end{array}$ & $\begin{array}{c}\text { A12 } \\
15\end{array}$ & $\begin{array}{c}\text { A14 } \\
166\end{array}$ & $\begin{array}{c}\text { A11 } \\
20\end{array}$ & $\begin{array}{c}\text { OA } \\
127 \\
\text { AI:450 }\end{array}$ & & & & & & & \\
\hline $\mathrm{Cr}$ & & & & & & $\begin{array}{c}\text { DW } \\
13\end{array}$ & $\begin{array}{c}\text { DW } \\
31\end{array}$ & 48 & & & & $\begin{array}{l}\text { A14 } \\
283\end{array}$ & $\begin{array}{c}\text { A09 } \\
32 \\
\text { AI:129 }\end{array}$ & $\begin{array}{l}\text { A10 } \\
209\end{array}$ & $\begin{array}{c}\text { A07 } \\
3\end{array}$ & $\begin{array}{c}\text { DW } \\
10\end{array}$ & $\begin{array}{c}\text { DW } \\
15\end{array}$ & $\begin{array}{l}\text { A20 } \\
590\end{array}$ & $\begin{array}{l}\text { A12 } \\
204\end{array}$ & $\begin{array}{c}\text { A14 } \\
166\end{array}$ & $\begin{array}{l}\text { A11 } \\
243\end{array}$ & $\begin{array}{c}\text { OA } \\
127 \\
\text { AI: } 450\end{array}$ & & & & & \\
\hline $\mathrm{Mn}$ & & & & & & & $\begin{array}{c}\text { DW } \\
13\end{array}$ & $\begin{array}{c}\text { DW } \\
31\end{array}$ & 48 & & & & $\begin{array}{l}\text { A14 } \\
283\end{array}$ & $\begin{array}{c}\text { A09 } \\
32 \\
\text { AI:129 }\end{array}$ & $\begin{array}{r}\text { A10 } \\
209\end{array}$ & $\begin{array}{c}\mathrm{A} 07 \\
3\end{array}$ & $\begin{array}{c}\text { DW } \\
10\end{array}$ & $\begin{array}{c}\text { DW } \\
15\end{array}$ & $\begin{array}{l}\text { A20 } \\
590\end{array}$ & $\begin{array}{l}\text { A12 } \\
204\end{array}$ & $\begin{array}{c}\text { A14 } \\
166\end{array}$ & $\begin{array}{l}\text { A11 } \\
204\end{array}$ & & & & & \\
\hline $\mathrm{Fe}$ & $\begin{array}{l}\text { RM } \\
142\end{array}$ & $\begin{array}{c}\text { A } 1 \\
322\end{array}$ & $\begin{array}{c}\mathrm{RM} \\
37\end{array}$ & $\begin{array}{c}\text { RM I } \\
34\end{array}$ & $\begin{array}{c}\text { RM } \\
96\end{array}$ & $\begin{array}{l}\text { A } \\
9\end{array}$ & $\begin{array}{c}\text { A } \\
536\end{array}$ & $\begin{array}{c}\text { A } \\
915\end{array}$ & $\begin{array}{c}\text { A } \\
552\end{array}$ & $\begin{array}{c}\text { A } \\
996\end{array}$ & $\begin{array}{c}\text { A } \\
912\end{array}$ & $\begin{array}{c}\text { A } \\
749\end{array}$ & $\begin{array}{c}\text { A } \\
739\end{array}$ & $\begin{array}{l}\text { A14 } \\
283 \\
\end{array}$ & $\begin{array}{c}\text { A09 } \\
32 \\
\text { AI:129 }\end{array}$ & $\begin{array}{l}\text { A10 } \\
267\end{array}$ & $\begin{array}{c}\text { A07 } \\
336 \\
\text { AI:1 }\end{array}$ & $\begin{array}{c}\text { RM+DW } \\
630 \\
\text { AI: } 6\end{array}$ & $\begin{array}{l}359 \\
\text { AI:16 }\end{array}$ & $\begin{array}{c}\text { A20 } \\
590 \\
\text { AI:30 }\end{array}$ & $\begin{array}{c}\text { A12 } \\
513 \\
\text { AI:35 }\end{array}$ & $\begin{array}{c}\text { A14 } \\
166 \\
\text { AI:30 }\end{array}$ & $\begin{array}{c}\text { A11 } \\
63 \\
\text { AI: } 860\end{array}$ & $\begin{array}{c}\text { OA } \\
127 \\
\mathrm{AI}: 450\end{array}$ & $\begin{array}{c}\text { OA } \\
25\end{array}$ & & \\
\hline Co & & & & & & & & & & & & & & & $\begin{array}{l}\text { A14 } \\
283\end{array}$ & $\begin{array}{c}\text { A09 } \\
32 \\
\text { AI:129 }\end{array}$ & $\begin{array}{l}\text { A10 } \\
209\end{array}$ & $\begin{array}{c}\text { A07 } \\
3\end{array}$ & $\begin{array}{c}\text { DW } \\
10\end{array}$ & $\begin{array}{c}\text { DW } \\
15\end{array}$ & $\begin{array}{l}\text { A20 } \\
590\end{array}$ & $\begin{array}{l}\text { A12 } \\
204\end{array}$ & $\begin{array}{c}\text { A14 } \\
166\end{array}$ & $\begin{array}{l}\text { A11 } \\
204\end{array}$ & & & \\
\hline $\mathrm{Ni}$ & $\begin{array}{c}\text { RM } \\
17\end{array}$ & & & & & & & & & $\begin{array}{c}\text { A } \\
599\end{array}$ & $\begin{array}{c}\mathrm{RM} \\
31\end{array}$ & $\begin{array}{c}\text { DW } \\
48\end{array}$ & $\begin{array}{l}\text { DW } \\
143\end{array}$ & $\begin{array}{c}\text { A } \\
483\end{array}$ & $\begin{array}{c}\text { DW } \\
40\end{array}$ & $\begin{array}{l}\text { A14 } \\
283\end{array}$ & $\begin{array}{c}\text { A09 } \\
32 \\
\text { AI: } 129\end{array}$ & $\begin{array}{l}\text { A10 } \\
209\end{array}$ & $\begin{array}{l}\text { A07 } \\
195\end{array}$ & $\begin{array}{c}\text { DW } \\
58\end{array}$ & $\begin{array}{c}\text { DW } \\
15\end{array}$ & $\begin{array}{l}\text { A20 } \\
590\end{array}$ & $\begin{array}{l}\text { A12 } \\
204\end{array}$ & $\begin{array}{c}\text { A14 } \\
166\end{array}$ & $\begin{array}{c}\text { A11 } \\
63 \\
\text { AI: } 860\end{array}$ & $\begin{array}{c}\text { OA } \\
127 \\
\text { AI: } 450\end{array}$ & $\begin{array}{c}\text { OA } \\
25\end{array}$ \\
\hline $\mathrm{Zn}$ & & & & & & & & & & & & & & & & & & $\begin{array}{l}\text { A14 } \\
283\end{array}$ & $\begin{array}{c}\text { A09 } \\
32 \\
\text { AI:129 }\end{array}$ & $\begin{array}{l}\text { A10 } \\
209\end{array}$ & & $\begin{array}{c}\text { DW } \\
10\end{array}$ & $\begin{array}{c}\text { DW } \\
72\end{array}$ & $\begin{array}{l}\text { A20 } \\
590\end{array}$ & & $\begin{array}{c}\text { A14 } \\
10\end{array}$ & $\begin{array}{c}\text { A11 } \\
63 \\
\text { AI: } 860 \\
\end{array}$ \\
\hline
\end{tabular}

Notes: the top entry indicates the type of collisional excitation data: A indicates UK APAP Network $R$-matrix data (the following numbers indicate the year of publication, i.e., A10 was published in 2010. OA indicates older UK APAP Network $R$-matrix data. RM indicates other $R$-matrix data, while DW distorted-wave data. I indicates interpolated data. The next entry is the number of bound levels present in the model. For the ions with autoionization levels, AI indicates their number. 


\subsection{Collisional Excitation from Protons}

Collisional excitation by proton impact is important whenever the energy separation between levels is very small. This is common in the fine-structure levels of the ground configurations, for which some rates are available from the literature, as described in [41], where the data included in the CHIANTI database are listed.

\subsection{Radiative Data}

As mentioned, the target description for the scattering calculations is often not as accurate as what can be obtained with some atomic structure codes, so the radiative rates, especially for the ground configuration, are routinely taken in CHIANTI from other sets of calculations. Accurate data for several important ions are now available. For example, the Multiconfiguration Hartree-Fock (MCHF) calculations [42] are available at NIST ${ }^{5}$. Multiconfiguration Dirac-Hartree-Fock (MCDHF) calculations with the various improvements (see e.g., $[43,44]$ ) of Ian Grant's relativistic atomic structure program GRASP are also available. Data for ions in the $\mathrm{C}, \mathrm{N}, \mathrm{B}, \mathrm{O}, \mathrm{F}, \mathrm{Ne}, \mathrm{P}, \mathrm{Si}, \mathrm{S}, \mathrm{Mg}, \mathrm{Al}$ isoelectronic sequences are now available, see [45] for a review.

The MCDHF calculations provide very accurate transition probabilities (with uncertainties estimated to be within a few percent), but also theoretical level energies typically close, within a few hundred Kaysers, to the experimental energies, whenever they are available. Within a series of publications, the MCDHF calculations have been used to assess the reliability of line identifications, finding errors in literature values and in NIST, as described in the next section.

\subsection{Experimental Energies and Line Identifications}

The reference experimental energies are those of the $\mathrm{NIST}^{6}$ compilation, although in some circumstances the CHIANTI team have used other sources if updates were available in the literature that had not been processed by the NIST team prior to CHIANTI releases. Examples in the past included the updates to ground configuration energies for many ions by [46,47] using high-resolution ultraviolet solar and stellar spectra from SoHO SUMER, HST STIS and ESO UVES spectra. An important advance at EUV wavelengths came in 2006 with high-resolution solar spectral imaging from Hinode EIS, which has yielded dozens of new spectral line identifications that have been incorporated into CHIANTI. Benchmarking the atomic data against EIS observations and laboratory plates for iron resulted in a significant improvement in our knowledge of the experimental energies for the coronal iron ions, as reviewed in [20]. Most of these new energies have been confirmed by the above-mentioned MCDHF calculations, and by EBIT measurements, as shown e.g., in [48]. The situation in the soft X-rays (50-150 $\AA$ ) is significantly improved now for the coronal iron ions, but a large fraction of the lines still awaits identifications and atomic data, as reviewed in [49]. A similar situation is present also in the UV. Further laboratory measurements and atomic calculations are needed.

\subsection{Photoexcitation (PE)}

Photoexcitation (PE) is a fundamental process, whenever electron densities are sufficiently low, as in the outer solar corona and most astrophysical plasma. PE effects on the level balance of an ion were included in CHIANTI version 4 [41]. Either black-body or user-defined radiation fields could be used. In the latter case, Doppler dimming effects (when the local plasma sees a Doppler-shifted incoming radiation) can also be included.

5 https://nlte.nist.gov/MCHF/periodic.html.

6 https://physics.nist.gov/PhysRefData/ASD/levels_form.html. 


\section{Atomic Processes Affecting the Ion Charge State}

\subsection{Collisional Ionization (CI) Rates}

The availability of theoretical cross-sections for direct ionization (DI) via electron impact is much poorer, compared to the $\mathrm{CE}$ rates. Several groups have provided accurate calculations for a few ions and neutrals, see e.g., $[50,51]$.

Laboratory measurements are available for several ions, but significant discrepancies among laboratory measurements and calculations still exist. Even less data exists on excitation-autoionization (EA) cross-sections. A significant review of CI rates for the ground states of all the main ions was produced by [52], using the FAC code [53]. The cross-sections and rates, sometimes adjusted to experiment, have been stored in the CHIANTI database since version 6, and have been widely used in astrophysics. Laboratory measurements were reviewed for several ions by [54], finding overall good agreement with the [52] results.

As it turns out that CI from (populated) excited states is very important for the calculation of the charge state distribution, an effort is ongoing to calculate DI with FAC, and EA with the available $R$-matrix CE rates. Rates for the carbon and oxygen ions have been produced [55,56], and further work is ongoing.

\subsection{Photoionization (PI)}

Photoionization processes are pervasive in astrophysics, but have often been overlooked in solar physics. Aside from Kramers' semi-classical treatment, PI cross-sections have been calculated with the R-matrix method [57] and the perturbative, or "distorted wave" (DW) method [58]. The reference cross-sections are those of the Opacity Project (OP, see [59]). However, the thresholds need to be adjusted. Within CHIANTI, we provide Kramers' cross-sections with the Gaunt factors as calculated by [60], and for the ground states of the ions the total cross-sections by [61], which are analytical fits to the smoothed OP data, with the thresholds adjusted.

\subsection{Recombination Rates}

Radiative recombination (RR) rate coefficients for entire isoelectronic sequences were carried out by [62] using the FAC code and [63] using AUTOSTRUCTURE. The rates were obtained from the photoionization cross-sections calculated with the DW method [58] and the principle of detail balance, assuming thermal electrons.

CHIANTI originally only had a compilation of total RR rate coefficients, mostly from [63]. However, to take into account cascading effects due to RR into high-lying levels, some approximate corrections were introduced, following [62].

Since version 9 of CHIANTI [64], the final state-resolved RR rate coefficients provided by [63] have been included for some ions, for the bound levels. A two-ion collisional-radiative model (CRM) was developed to calculate the populations of the main autoionizing levels producing satellite lines in the X-rays [20]. The cascading effects from the excited levels into the populations of the lower levels are therefore now naturally included in the model ions, although we note that some of the RR can occur into high-lying levels that are not currently included in a model ion.

Final state-resolved dielectronic recombination (DR) rate coefficients have been calculated for several isoelectronic sequences with AUTOSTRUCTURE in a series of papers by the DR project [65]. These papers also showed good overall agreement with laboratory measurements. Further calculations for the most complex sequences are needed, however. The total DR rate coefficients for recombination from the ground states are included in CHIANTI. Regarding the DR rates, to avoid double counting, the total DR rate due to the few autoionizing levels included in the CHIANTI model is calculated and subtracted from the total DR.

However, as shown by [66], the DR rates are significantly suppressed with increasing electron densities. At intermediate densities, this is mainly caused by the excited states below the ionization 
limit being re-ionized via electron impact. The simplified collisional-radiative modeling (CRM) built at the time produced effective DR rates as a function of densities, as in [67]. One way to estimate the DR suppression is therefore to use the recent DR project rates and apply the variation with density found by [67]. This approximation has been adopted by [55,56] using directly the effective rates of [67], and by [68] using the empirical formulae of [69] which aim to reproduce the same effective rates. The [69] formulae will be introduced in CHIANTI version 10 to improve the modeling of high density plasma (on a side note, earlier empirical formulae by [70] were affected by a few problems). We note that the DR suppression significantly affects the charge states of some ions at even the relatively low densities of the solar corona, $10^{8} \mathrm{~cm}^{-3}$ [68].

In principle, both RR and DR rates can be obtained from the photoionization cross-sections calculated with the $R$-matrix method. However, a consistent database is not available. The OP cross-sections are not initial and final-state resolved so cannot be used for this purpose.

\subsection{Time-Dependent Ionization (TDI)}

It is now widely recognized in solar physics that TDI effects are very important in many cases. They are definitely very important in the highly dynamic chromosphere and transition region, but are also very relevant in the solar wind and dynamic events such as solar flares. Indeed in all these cases temporal variations much faster than the recombination timescales are observed. For recent reviews on this topic see [20,71]. TDI effects are also important in a range of astrophysical environments such as supernova explosions. Some TDI effects are presently included in some hydrodynamical (see, e.g., [72]) and MHD (see, e.g., [73]) models of the solar atmosphere. However, these effects are normally not included in a self-consistent way, and assume the zero-density approximation (only ionization and recombination rates connecting the ground states). Future improvements of CHIANTI will make level-resolved rates available so density effects can be included.

\subsection{Charge Exchange}

Charge exchange is an efficient ionization/recombination process at relatively low temperatures. It is an important process in most astrophysical plasma, and in the lower transition region in the case of the Sun. Detailed quantum-mechanical calculations are available for several ions, but are generally not widely available or used.

\section{Uncertainties on Atomic Rates}

Now that atomic data for most ions are available, the obvious next step is to start assessing their accuracy. Uncertainties in observed wavelengths have been collected in the series of benchmark papers by one of us (GDZ). They have been converted into uncertainties in the experimental energies, although they have not been included in CHIANTI releases, as they are only available for a few ions. Since version 8 , semi-empirically adjusted energies have also been added. A comparison between them and the few experimental energies available gives an indication of the uncertainty in the energies.

Uncertainties in the radiative rates (oscillator strengths and A-values) can be assessed by comparing the values in the length and velocity forms [45], or more generally comparing the results of different calculations, as done e.g., for Fe XIII [74] and for N IV [75]. Other useful information is provided by laboratory measurements of radiative lifetimes. Some examples are provided in [20].

Uncertainties on CE rates can also be assessed by comparing the results of different scattering calculations, and by taking into account the various factors, as briefly discussed in [20]. Ultimately, the overall uncertainty on the line intensities can be assessed with Monte Carlo simulations such as in [74], and by comparisons with well-calibrated spectra, as carried out in a series of benchmark papers following the [76] method, as reviewed in [20]. 


\section{Non-Maxwellian Electron Distributions (NMED)}

There are several instances in solar physics where NMED are known or expected to be present, see the review by [71]. For example, in situ measurements the solar wind show that the electron distribution is very anisotropic and non-Maxwellian. Also, during the impulsive phase of solar flares bremsstrahlung emission in the X-rays clearly indicates that electrons are non-thermal. The solar transition region, connecting the chromosphere and the corona is subject to strong gradients and is expected to be affected by NMED. In this regard, [77] showed that the unexplained strong enhancements in Si IV could be caused by NMED. Recently, evidence for NMED effects has been found in coronal lines in active regions, see the most recent paper by [78].

NMED effects are very common in laboratory plasma (see, e.g., Bartiromo et al. [79], Glenzer et al. [80]). They have also been proposed to explain the long-standing discrepancy between elemental abundances obtained from collisionally excited or optical recombination lines in nebular astrophysics, although detailed collisional-radiative modeling seem to rule that out (see e.g., Fang et al. [81], storey and Sochi [82] and references therein).

To model the effects on the CE rates, one should integrate CE cross-sections with a NMED. This is not trivial as a database of such cross-sections is not available yet. The UK APAP network identified ways to integral average the cross-sections, to reduce the data size (typically over $10 \mathrm{~Gb}$ for one ion). An alternative approach is to model the NMED as a sum of Maxwellians, and calculate the CE rates accordingly. This was introduced in CHIANTI version 5 [83]. In this way, for example, $\kappa$-distributions can be modeled, see e.g., [84]. Another approach was followed by [85] with the KAPPA ${ }^{7}$ package, a modified version of the CHIANTI version 7 database.

\section{Towards Collisional-Radiative Modeling}

As briefly mentioned, we developed a collisional-radiative modeling and introduced it in CHIANTI version 9, to calculate the intensities of the $X$-ray satellite lines of the main ions. These are state-resolved two-ion models that include some autoionizing levels, but only have the lower bound states. The significant novelty over any other previous models was the inclusion of dielectronic capture from excited states of the recombining ion, which produces interesting density-dependent effects on the intensities of the satellite lines.

A first step towards a proper modeling of the ion populations (neglecting the autoionizing levels) is the level-resolved collisional-radiative modeling developed for the carbon ions by [55]. All the J-resolved states in the six ionization stages, plus the bare nuclei have been included in a single matrix formulation, and level populations of all the ions obtained at once. The CI from the metastable levels have a significant effect, as the DR suppression does. The DR suppression was however only included approximately, as mentioned above. A similar model was built for oxygen [56]; an example of the resulting ion charge states is given in Figure 2.

Such effects are of great relevance for the solar transition region and current solar instruments devoted to this part of the atmosphere, such as IRIS [86] and Solar Orbiter SPICE [87]. Density-dependent effects are also important for any plasma at relatively high densities, such as laboratory plasma or astrophysical plasma close to black holes (AGN).

To properly calculate the DR suppression, a full CRM with resolved bound states reaching the ionization limit needs to be built. This is non-trivial, but has the additional advantage that lines mostly formed by recombination or by cascades following recombination can also be properly modeled. We note that UV solar spectra are full of emission lines of neutrals or singly ionized atoms that are decays from high-lying levels. Models for these transitions have been lacking, unlike in

7 http://kappa.asu.cas.cz. 
nebular astrophysics, where detailed models of the optical recombination lines for several ions have been developed.

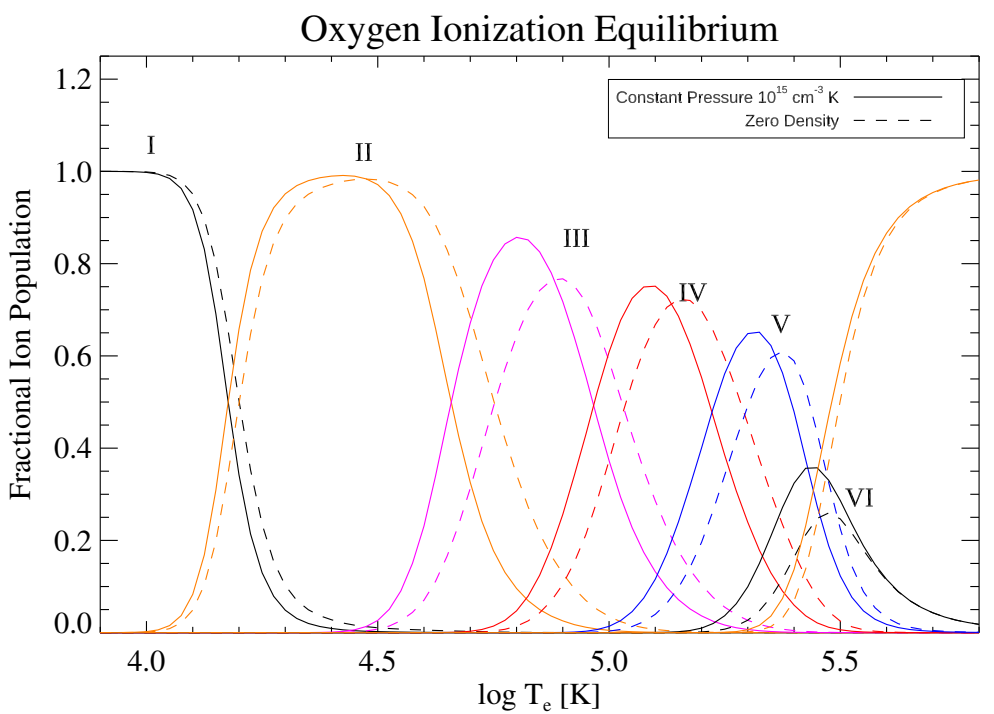

Figure 2. Relative ion populations for oxygen, assuming ionization equilibrium. The full lines indicate the values with all the density-dependent effects included (for a constant pressure), while the dashed lines show the zero density case.

While work on the carbon ions is ongoing, a full CRM for helium in the solar corona has been built [30]. Several issues regarding the calculation of the relevant atomic rates have been uncovered, clearly indicating the complexity of such models and the difficulty in obtaining accurate atomic rates.

It has become increasingly clear however that even more complex self-consistent atomic models are needed. For example, a long-standing problem in solar physics are the enhanced intensities of some transition-region lines such as Si IV. As we have mentioned, enhancements can be produced either by time-dependent ionization, non-Maxwellian distributions or other density-dependent effects, and at the moment it is not clear which one is the dominant factor [88].

The real challenge in the future is to build models where self-consistently all the above-mentioned physical effects are included. Distribution within CHIANTI will likely proceed in steps. As mentioned, DR suppression in an approximate form is being included in version 10. Similarly, effective ionization rates (function of electron density and temperature) could be introduced, pre-calculating the charge states using full or simplified models. PI effects are also relatively easy to introduce, as PI cross-sections for most ions are readily available, for example from the Opacity Project.

The increasingly large models require much larger storage and computing time to read and perform the calculations. The CHIANTI format (ASCII files) is popular but not efficient. In the future, more structured formats such as HDF or FITS binary tables will be used to speed up the reading of the data.

By default, the CHIANTI level population calculations are performed as required based on the user's inputs. This can mean that a complete synthetic spectrum including all species in CHIANTI can take around 10 min to compute. Recently, a new option has been implemented in CHIANTI to use population lookup tables. That is, pre-computed tables of level populations calculated on a grid of temperatures and densities. The advantage of pre-computing level populations rather than, e.g., transition emissivities, is that the data-set is much smaller. For example, 0.5 GB compared to $>10 \mathrm{~GB}$ for a typical range of coronal densities. The accuracy of the interpolated populations is typically $<1 \%$, which is usually acceptable given the uncertainties in the underlying atomic data. The method for implementing the lookup tables is described in detail in CHIANTI Technical Report No. 16, available at https:/ / chiantidatabase.org/tech_reports. 


\section{Distribution and Maintenance of CHIANTI}

CHIANTI consists of the atomic database and two software packages, one written in IDL, the other in Python. The software packages are independent of each other but both use the same database, which is largely a collection of ASCII files. Both the database and software are freely available to all scientists, although IDL itself is a proprietary programming language that requires a subscription.

The database and IDL package are distributed as individual tar files through the CHIANTI website at https: / / chiantidatabase.org. Each is assigned a version number and they are maintained through a subversion repository stored on a commercial server that is rented by the CHIANTI team. The Python package (ChiantiPy) is distributed through a github repository.

IDL has been widely used in the Solar Physics community for several decades, and a large library of IDL routines has been built up in the Solarsoft ${ }^{8}$ distribution, mostly for providing analysis software for NASA space missions. The CHIANTI database and the CHIANTI IDL package are distributed through Solarsoft, and this is the most common way of accessing CHIANTI in this field. Solarsoft can be configured to be automatically updated, ensuring the latest version of CHIANTI is always available.

\section{Conclusions}

In current and future astrophysical missions, high-resolution spectroscopy is featuring prominently. Therefore, we can expect further challenges to the available atomic data and models. We have still a long way before reaching completeness in atomic rates for all the important ions. However, for most cases several improved calculations are available. Comparisons between them, as well as against observed spectra, are providing an overall satisfying picture, where emissivities for at least the strongest lines can now be calculated with a relatively small uncertainty, typically of the order of the uncertainties in the observations themselves (10-30\%). The current situation in terms of rates for processes within an ion is relatively satisfactory. In the future, more emphasis will be devoted to assessing the accuracy of available data, and improving the modelling of ionization/recombination and non-equilibrium processes.

Author Contributions: Conceptualization: G.D.Z.; Writing—original draft: G.D.Z., P.R.Y.; Writing一review \& editing: G.D.Z., P.R.Y. All authors have read and agreed to the published version of the manuscript.

Funding: G.D.Z. research has been funded by STFC (UK) via the consolidated grants to the atomic astrophysics group (AAG) at DAMTP, University of Cambridge (ST/P000665/1. and ST/T000481/1). P.R.Y. acknowledges support from the NASA Heliophysics Data Environment Enhancements program.

Acknowledgments: We would like to thank Roger Dufresne for comments on this manuscript.

Conflicts of Interest: The authors declare no conflict of interest.

\section{References}

1. Young, P.R.; Dere, K.P.; Landi, E.; Del Zanna, G.; Mason, H.E. The CHIANTI atomic database. J. Phys. B At. Mol. Phys. 2016, 49, 074009. [CrossRef]

2. Dere, K.P.; Landi, E.; Mason, H.E.; Monsignori Fossi, B.C.; Young, P.R. CHIANTI-An atomic database for emission lines. Astron. Astrophys. Suppl. Ser. 1997, 125, 149-173. [CrossRef]

3. Ferland, G.J.; Chatzikos, M.; Guzmán, F.; Lykins, M.L.; van Hoof, P.A.M.; Williams, R.J.R.; Abel, N.P.; Badnell, N.R.; Keenan, F.P.; Porter, R.L.; et al. The 2017 Release Cloudy. RMXAA 2017, 53, 385-438.

4. Ercolano, B.; Young, P.R.; Drake, J.J.; Raymond, J.C. X-Ray Enabled MOCASSIN: A Three-dimensional Code for Photoionized Media. Astrophys. J. Suppl. Ser. 2008, 175, 534-542. [CrossRef]

5. Bautista, M.A.; Kallman, T.R. The XSTAR Atomic Database. Astrophys. J. Suppl. Ser. 2001, 134, $139-149$. [CrossRef]

8 https://sohowww.nascom.nasa.gov/solarsoft/. 
6. Kerzendorf, W.E.; Sim, S.A. A spectral synthesis code for rapid modelling of supernovae. Mon. Not. R. Astron. Soc. 2014, 440, 387-404. [CrossRef]

7. Smith, R.K.; Brickhouse, N.S.; Liedahl, D.A.; Raymond, J.C. Collisional Plasma Models with APEC/APED: Emission-Line Diagnostics of Hydrogen-like and Helium-like Ions. Astrophys. J. Lett. 2001, 556, L91-L95. [CrossRef]

8. Kashyap, V.; Drake, J.J. PINTofALE : Package for the interactive analysis of line emission. Bull. Astron. Soc. India 2000, 28, 475-476.

9. Judge, P.G.; Meisner, R.W. The 'HAO Spectral Diagnostics Package' (HAOS-Diaper). In Proceedings of the Third SOHO Workshop on Solar Dynamic Phenomena and Solar Wind Consequences, Estes Park, CO, USA, 26-29 September 1994; Hunt, J.J., Ed.; ESA Special Publication: Paris, France, 1994; Volume 373, p. 67.

10. Kaastra, J.S.; Mewe, R.; Nieuwenhuijzen, H. SPEX: A New Code for Spectral Analysis of X E UV Spectra;UV and X-ray Spectroscopy of Astrophysical and Laboratory Plasmas: Cambridge, MA, USA, 1996; pp. 411-414.

11. Albert, D.; Anton, B.K.; Ba, Y.-A.; Babikov, Y.L.; Bollard, P.; Boudon, V.; Delahaye, F.; Del Zanna, G.; Dimitrijević, M.S.; Drouin, B.; et al. A decade with VAMDC: results and ambitio. Atoms 2020, submitted for publication.

12. Gombosi, T.I.; van der Holst, B.; Manchester, W.B.; Sokolov, I.V. Extended MHD modeling of the steady solar corona and the solar wind. Living Rev. Sol. Phys. 2018, 15, 4. [CrossRef]

13. Bradshaw, S.J.; Mason, H.E. A self-consistent treatment of radiation in coronal loop modelling. Astron. Astrophys. 2003, 401, 699-709. [CrossRef]

14. Allred, J.C.; Kowalski, A.F.; Carlsson, M. A Unified Computational Model for Solar and Stellar Flares. Astrophys. J. 2015, 809, 104. [CrossRef]

15. Del Zanna, G.; O’Dwyer, B.; Mason, H.E. SDO AIA and Hinode EIS observations of warm loops. Astron. Astrophys. 2011, 535, A46. [CrossRef]

16. Boerner, P.F.; Testa, P.; Warren, H.; Weber, M.A.; Schrijver, C.J. Photometric and Thermal Cross-calibration of Solar EUV Instruments. Sol. Phys. 2014, 289, 2377-2397. [CrossRef]

17. Hummer, D.G.; Berrington, K.A.; Eissner, W.; Pradhan, A.K.; Saraph, H.E.; Tully, J.A. Atomic data from the IRON Project. 1: Goals and methods. Astron. Astrophys. 1993, 279, 298-309.

18. Berrington, K.A.; Eissner, W.B.; Norrington, P.H. RMATRX1: Belfast atomic R-matrix codes. Comput. Phys. Commun. 1995, 92, 290-420. [CrossRef]

19. Burgess, A.; Tully, J.A. On the Analysis of Collision Strengths and Rate Coefficients. Astron. Astrophys. 1992, $254,436$.

20. Del Zanna, G.; Mason, H.E. XUV Spectroscopy. Living Rev. Sol. Phys. 2018, 15, 5. [CrossRef]

21. Griffin, D.C.; Badnell, N.R.; Pindzola, M.S. R-matrix electron-impact excitation cross sections in intermediate coupling: An MQDT transformation approach. J. Phys. B At. Mol. Phys. 1998, 31, 3713-3727. [CrossRef]

22. Badnell, N.R.; Del Zanna, G.; Fernández-Menchero, L.; Giunta, A.S.; Liang, G.Y.; Mason, H.E.; Storey, P.J. Atomic processes for astrophysical plasmas. J. Phys. B At. Mol. Phys. 2016, 49, 094001. [CrossRef]

23. Fernández-Menchero, L.; Zatsarinny, O.; Bartschat, K. Electron impact excitation of $\mathrm{N}^{3+}$ using the B-spline R-matrix method: Importance of the target structure description and the size of the close-coupling expansion. J. Phys. B At. Mol. Phys. 2017, 50, 065203. [CrossRef]

24. Zatsarinny, O. BSR: B-spline atomic R-matrix codes. Comput. Phys. Commun. 2006, 174, 273-356. [CrossRef]

25. Zatsarinny, O.; Bartschat, K. The B-spline R-matrix method for atomic processes: Application to atomic structure, electron collisions and photoionization. J. Phys. B At. Mol. Phys. 2013, 46, 112001. [CrossRef]

26. Bray, I.; Stelbovics, A.T. Convergent close-coupling calculations of electron-hydrogen scattering. Phys. Rev. A 1992, 46, 6995-7011. [CrossRef]

27. Mao, J.; Badnell, N.R.; Del Zanna, G. R-matrix electron-impact excitation data for the C-like iso-electronic sequence. Astron. Astrophys. 2020, 634, A7. [CrossRef]

28. Del Zanna, G.; Dere, K.P.; Young, P.R.; Landi, E.; Mason, H.E. CHIANTI-An atomic database for emission lines. Version 8. Astron. Astrophys. 2015, 582, A56. [CrossRef]

29. Del Zanna, G.; Storey, P.J.; Badnell, N.R.; Mason, H.E. Atomic data for astrophysics: Fe x soft X-ray lines. Astron. Astrophys. 2012, 541, A90. [CrossRef]

30. Del Zanna, G.; Storey, P.J.; Badnell, N.R.; Andretta, V. Helium Line Emissivities in the Solar Corona. Astrophys. J. 2020, 898, 72. [CrossRef] 
31. Fernández-Menchero, L.; Del Zanna, G.; Badnell, N.R. Scaling of collision strengths for highly-excited states of ions of the H- and He-like sequences. Astron. Astrophys. 2016, 592, A135. [CrossRef]

32. Del Zanna, G.; Storey, P.J.; Mason, H.E. Atomic data from the IRON project. LXVIII. Electron impact excitation of Fe XI. Astron. Astrophys. 2010, 514, A40+. [CrossRef]

33. Griffin, D.C.; Pindzola, M.S.; Badnell, N.R. Electron-impact excitation of Fe ${ }^{7+}$. Astron. Astrophys. Suppl. Ser. 2000, 142, 317-323. [CrossRef]

34. Tayal, S.S.; Zatsarinny, O. Effective Collision Strengths for Electron-impact Excitation of Fe VIII. Astrophys. J. 2011, 743, 206. [CrossRef]

35. Del Zanna, G. Benchmarking atomic data for astrophysics: Fe VIII EUV lines. Astron. Astrophys. 2009, 508, 513-524. [CrossRef]

36. Del Zanna, G.; Badnell, N.R. Atomic data for astrophysics: Improved collision strengths for Fe VIII. Astron. Astrophys. 2014, 570, A56. [CrossRef]

37. Witthoeft, M.C.; Badnell, N.R. Atomic data from the IRON Project. LXV. Electron-impact excitation of Fe6+. Astron. Astrophys. 2008, 481, 543-551. [CrossRef]

38. Del Zanna, G. Benchmarking atomic data for astrophysics: Fe VII and other cool lines observed by Hinode EIS. Astron. Astrophys. 2009, 508, 501-511. [CrossRef]

39. Young, P.R.; Landi, E. Chianti-An Atomic Database for Emission Lines. XI. Extreme-Ultraviolet Emission Lines of Fe VII, Fe VIII, and Fe IX Observed by Hinode/EIS. Astrophys. J. 2009, 707, 173-192. [CrossRef]

40. Tayal, S.S.; Zatsarinny, O. Electron Impact Excitation Collision Strengths for Extreme Ultraviolet Lines of Fe VII. Astrophys. J. 2014, 788, 24. [CrossRef]

41. Young, P.R.; Del Zanna, G.; Landi, E.; Dere, K.P.; Mason, H.E.; Landini, M. CHIANTI-An Atomic Database for Emission Lines. VI. Proton Rates and Other Improvements. Astrophys. J. Suppl. Ser. 2003, 144, 135-152. [CrossRef]

42. Froese Fischer, C.; Godefroid, M.; Brage, T.; Jönsson, P.; Gaigalas, G. Advanced multiconfiguration methods for complex atoms: I. Energies and wave functions. J. Phys. B At. Mol. Phys. 2016, 49, 182004. [CrossRef]

43. Jönsson, P.; He, X.; Froese Fischer, C.; Grant, I.P. The grasp2K relativistic atomic structure package. Comput. Phys. Commun. 2007, 177, 597-622. [CrossRef]

44. Jönsson, P.; Gaigalas, G.; Bieroń, J.; Fischer, C.F.; Grant, I.P. New version: GRASP2K relativistic atomic structure package. Comput. Phys. Commun. 2013, 184, 2197-2203. [CrossRef]

45. Jönsson, P.; Gaigalas, G.; Rynkun, P.; Radžiūtė, L.; Ekman, J.; Gustafsson, S.; Hartman, H.; Wang, K.; Godefroid, M.; Froese Fischer, C.; et al. Multiconfiguration Dirac-Hartree-Fock Calculations with Spectroscopic Accuracy: Applications to Astrophysics. Atoms 2017, 5, 16. [CrossRef]

46. Feldman, U.; Doschek, G.A. Improved low-lying energy levels determined from solar coronal forbidden and spin-forbidden lines in the $5001500 \AA$ range. At. Data Nucl. Data Tables 2007, 93, 779-806. [CrossRef]

47. Young, P.R.; Feldman, U.; Lobel, A. Forbidden and Intercombination Lines of RR Telescopii: Wavelength Measurements and Energy Levels. Astrophys. J. Suppl. Ser. 2011, 196, 23. [CrossRef]

48. Beiersdorfer, P.; Träbert, E.; Lepson, J.K.; Brickhouse, N.S.; Golub, L. High-resolution Laboratory Measurements of Coronal Lines in the 198-218 A Region. Astrophys. J. 2014, 788, 25. [CrossRef]

49. Del Zanna, G. Benchmarking atomic data for astrophysics: A first look at the soft X-ray lines. Astron. Astrophys. 2012, 546, A97. [CrossRef]

50. Ballance, C.P.; Ludlow, J.A.; Pindzola, M.S.; Loch, S.D. Electron-impact ionization of ground and metastable neon. J. Phys. B At. Mol. Phys. 2009, 42, 175202. [CrossRef]

51. Loch, S.D.; Ballance, C.P.; Wu, D.; Abdel-Naby, S.A.; Pindzola, M.S. Electron-impact ionization of Al. J. Phys. B At. Mol. Phys. 2012, 45, 065201. [CrossRef]

52. Dere, K.P. Ionization rate coefficients for the elements hydrogen through zinc. Astron. Astrophys. 2007, 466, 771-792. [CrossRef]

53. Gu, M.F. The flexible atomic code. Can. J. Phys. 2008, 86, 675-689. [CrossRef]

54. Hahn, M. Electron impact ionization of stored highly charged ions. J. Phys. Conf. Ser. 2014, 488, 012050. [CrossRef]

55. Dufresne, R.P.; Del Zanna, G. Modelling ion populations in astrophysical plasmas: Carbon in the solar transition region. Astron. Astrophys. 2019, 626, A123. [CrossRef]

56. Dufresne, R.P.; Del Zanna, G.; Badnell, N.R. Effects of density on the oxygen ionization equilibrium in collisional plasmas. Mon. Not. R. Astron. Soc. 2020, 497, 1443-1456. [CrossRef] 
57. Berrington, K.A.; Burke, P.G.; Butler, K.; Seaton, M.J.; Storey, P.J.; Taylor, K.T.; Yan, Y. Atomic data for opacity calculations. II. Computational methods. J. Phys. B At. Mol. Phys. 1987, 20, 6379-6397. [CrossRef]

58. Badnell, N.R.; Seaton, M.J. On the importance of inner-shell transitions for opacity calculations. J. Phys. B At. Mol. Phys. 2003, 36, 4367-4385. [CrossRef]

59. Seaton, M.J.; Yan, Y.; Mihalas, D.; Pradhan, A.K. Opacities for Stellar Envelopes. Mon. Not. R. Astron. Soc. 1994, 266, 805. [CrossRef]

60. Karzas, W.J.; Latter, R. Electron Radiative Transitions in a Coulomb Field. Astrophys. J. Suppl. Ser. 1961, 6, 167. [CrossRef]

61. Verner, D.A.; Yakovlev, D.G. Analytic FITS for partial photoionization cross sections. Astron. Astrophys. Suppl. Ser. 1995, 109, 125-133.

62. Gu, M.F. Indirect X-Ray Line-Formation Processes in Iron L-Shell Ions. Astrophys. J. 2003, 582, 1241-1250. [CrossRef]

63. Badnell, N.R. Radiative Recombination Data for Modeling Dynamic Finite-Density Plasmas. Astrophys. J. Suppl. Ser. 2006, 167, 334-342. [CrossRef]

64. Dere, K.P.; Del Zanna, G.; Young, P.R.; Landi, E.; Sutherland, R.S. CHIANTI-An Atomic Database for Emission Lines. XV. Version 9, Improvements for the X-Ray Satellite Lines. Astrophys. J. Suppl. Ser. 2019, 241, 22. [CrossRef]

65. Badnell, N.R.; O’Mullane, M.G.; Summers, H.P.; Altun, Z.; Bautista, M.A.; Colgan, J.; Gorczyca, T.W.; Mitnik, D.M.; Pindzola, M.S.; Zatsarinny, O. Dielectronic recombination data for dynamic finite-density plasmas. I. Goals and methodology. Astron. Astrophys. 2003, 406, 1151-1165. [CrossRef]

66. Burgess, A.; Summers, H.P. The Effects of Electron and Radiation Density on Dielectronic Recombination. Astrophys. J. 1969, 157, 1007. [CrossRef]

67. Summers, H.P. The ionization equilibrium of hydrogen-like to argon-like ions of elements. Mon. Not. R. Astron. Soc. 1974, 169, 663-680. [CrossRef]

68. Young, P.R. Element Abundance Ratios in the Quiet Sun Transition Region Astrophys. J. 2018, 855, 15. [CrossRef]

69. Nikolić, D.; Gorczyca, T.W.; Korista, K.T.; Chatzikos, M.; Ferland, G.J.; Guzmán, F.; van Hoof, P.A.M.; Williams, R.J.R.; Badnell, N.R. Suppression of Dielectronic Recombination Due to Finite Density Effects. II. Analytical Refinement and Application to Density-dependent Ionization Balances and AGN Broad-line Emission. Astrophys. J. Suppl. Ser. 2018, 237, 41. [CrossRef]

70. Nikolić, D.; Gorczyca, T.W.; Korista, K.T.; Ferland, G.J.; Badnell, N.R. Suppression of Dielectronic Recombination due to Finite Density Effects. Astrophys. J. 2013, 768, 82. [CrossRef]

71. Dudík, J.; Dzifčáková, E.; Meyer-Vernet, N.; Del Zanna, G.; Young, P.R.; Giunta, A.; Sylwester, B.; Sylwester, J.; Oka, M.; Mason, H.E. Nonequilibrium Processes in the Solar Corona, Transition Region, Flares, and Solar Wind (Invited Review). Sol. Phys. 2017, 292, 100. [CrossRef]

72. Bradshaw, S.J.; Del Zanna, G.; Mason, H.E. On the consequences of a non-equilibrium ionisation balance for compact flare emission and dynamics. Astron. Astrophys. 2004, 425, 287-299. [CrossRef]

73. Martínez-Sykora, J.; De Pontieu, B.; Hansteen, V.H.; Gudiksen, B. Time Dependent Nonequilibrium Ionization of Transition Region Lines Observed with IRIS. Astrophys. J. 2016, 817, 46. [CrossRef]

74. Yu, X.; Del Zanna, G.; Stenning, D.C.; Cisewski-Kehe, J.; Kashyap, V.L.; Stein, N.; van Dyk, D.A.; Warren, H.P.; Weber, M.A. Incorporating Uncertainties in Atomic Data into the Analysis of Solar and Stellar Observations: A Case Study in Fe XIII. Astrophys. J. 2018, 866, 146. [CrossRef]

75. Del Zanna, G.; Fernández-Menchero, L.; Badnell, N.R. Uncertainties on atomic data. A case study: N IV. Mon. Not. R. Astron. Soc. 2019, 484, 4754-4759. [CrossRef]

76. Del Zanna, G.; Berrington, K.A.; Mason, H.E. Benchmarking atomic data for astrophysics: Fe X. Astron. Astrophys. 2004, 422, 731-749. [CrossRef]

77. Dudík, J.; Del Zanna, G.; Dzifčáková, E.; Mason, H.E.; Golub, L. Solar Transition Region Lines Observed by the Interface Region Imaging Spectrograph: Diagnostics for the O IV and Si IV Lines. Astrophys. J. Lett. 2014, 780, L12. [CrossRef]

78. Lörinčík, J.; Dudík, J.; del Zanna, G.; Dzifčáková, E.; Mason, H.E. Plasma Diagnostics from Active Region and Quiet-Sun Spectra Observed by Hinode/EIS: Quantifying the Departures from a Maxwellian Distribution. Astrophys. J. 2020, 893, 34. [CrossRef] 
79. Bartiromo, R.; Bombarda, F.; Giannella, R. Spectroscopic study of nonthermal plasmas. Phys. Rev. A 1985, 32, 531-537. [CrossRef]

80. Glenzer, S.H.; Rosmej, F.B.; Lee, R.W.; Back, C.A.; Estabrook, K.G.; MacGowan, B.J.; Shepard, T.D.; Turner, R.E. Measurements of Suprathermal Electrons in Hohlraum Plasmas with X-Ray Spectroscopy. Phys. Rev. Lett. 1998, 81, 365-368. [CrossRef]

81. Fang, X.; Storey, P.J.; Liu, X.W. New effective recombination coefficients for nebular N ii lines. Astron. Astrophys. 2011, 530, A18. [CrossRef]

82. Storey, P.J.; Sochi, T. Emission and recombination coefficients for hydrogen with $\kappa$-distributed electron energies. Mon. Not. R. Astron. Soc. 2015, 446, 1864-1866. [CrossRef]

83. Landi, E.; Del Zanna, G.; Young, P.R.; Dere, K.P.; Mason, H.E.; Landini, M. CHIANTI-An Atomic Database for Emission Lines. VII. New Data for X-Rays and Other Improvements. Astrophys. J. Suppl. Ser. 2006, 162, 261-280. [CrossRef]

84. Hahn, M.; Savin, D.W. A Simple Method for Modeling Collision Processes in Plasmas with a Kappa Energy Distribution. Astrophys. J. 2015, 809, 178. [CrossRef]

85. Dzifčáková, E.; Dudík, J.; Kotrč, P.; Fárník, F.; Zemanová, A. KAPPA: A Package for Synthesis of Optically Thin Spectra for the Non-Maxwellian $\kappa$-distributions Based on the Chianti Database. Astrophys. J. Suppl. Ser. 2015, 217, 14. [CrossRef]

86. De Pontieu, B.; Title, A.M.; Lemen, J.R.; Kushner, G.D.; Akin, D.J.; Allard, B.; Berger, T.; Boerner, P.; Cheung, M.; Chou, C.; et al. The Interface Region Imaging Spectrograph (IRIS). Sol. Phys. 2014, 289, 2733-2779. [CrossRef]

87. Anderson, M.; Appourchaux, T.; Auchère, F.; Aznar Cuadrado, R.; Barbay, J.; Baudin, F.; Beardsley, S.; Bocchialini, K.; Borgo, B.; Bruzzi, D.; et al. The Solar Orbiter SPICE instrument-An extreme UV imaging spectrometer. $A \mathcal{E} A$ 2019. [CrossRef]

88. Polito, V.; Del Zanna, G.; Dudík, J.; Mason, H.E.; Giunta, A.; Reeves, K.K. Density diagnostics derived from the $\mathrm{O}$ iv and $\mathrm{S}$ iv intercombination lines observed by IRIS. Astron. Astrophys. 2016, 594, A64. [CrossRef]

(c) 2020 by the authors. Licensee MDPI, Basel, Switzerland. This article is an open access article distributed under the terms and conditions of the Creative Commons Attribution (CC BY) license (http:/ / creativecommons.org/licenses/by/4.0/). 